\title{
The impact of spousal violence on the children: A pastoral care approach
}

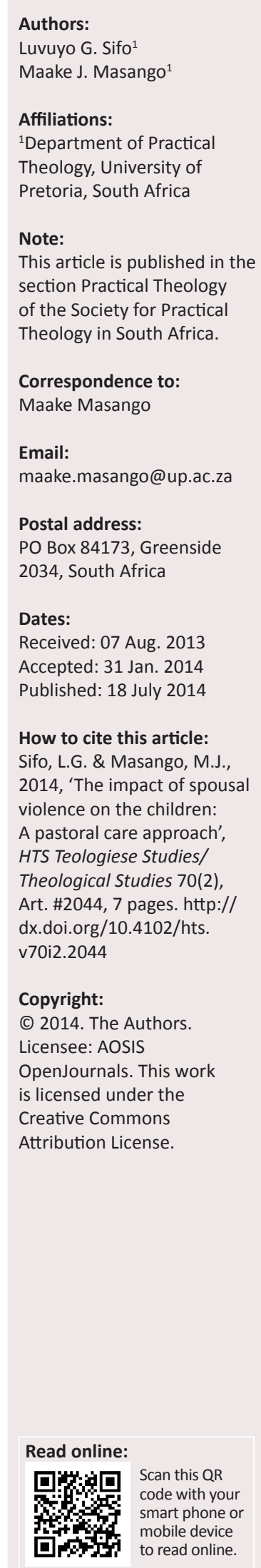

This article investigates the impact of spousal violence on children. Spousal violence in the home affects children negatively and its impact goes beyond their childhood years into adulthood. Some children become dysfunctional in life as a result of their exposure to violence between their parents. These children may exhibit symptoms associated with post-traumatic stress disorder (PTSD) later on in life. A case study of a family exposed to violence was undertaken. Findings from this case scenario were measured against existing literature. A pastoral care method of responding to the victims is proposed in order for them to be healed.

\section{Introduction}

The author is a pastoral therapist and an ordained minister with one of the large Christian denominations in South Africa. As a child he was exposed to violence between his parents in his home. As a trauma therapist, he sees people who live with debilitating consequences of having been exposed to violence within their families as children. In his quest to bring about wholeness to these people through pastoral care and counselling, he finds himself conflicted in his own trauma and therefore unable to help his clients. This article aims to empower other pastoral therapists with the skills to care for people who were exposed to violence as children.

\section{Case study of exposure to spousal violence}

Gcobani $^{1}$ is the firstborn son of an unmarried mother. He and his sister never knew their biological father. They were raised by their grandmother in a rural location of the Eastern Cape in South Africa. Their mother Bongi was working in the textile industry in Butterworth. Gcobani would pay monthly visits to his mother in order to collect money for food and other necessities that were needed by the family. It was during such visits when he noticed that his mother was living with a man called Sandi. At first, Sandi showed love and care towards Gcobani. He addressed Gcobani as his son and provided for his needs. Soon afterwards, Bongi and Sandi were married. This meant that Gcobani and his sister were now Sandi's stepchildren. The children were excited to finally have someone they could relate to as a father.

During one of his visits, Gcobani noticed something upsetting about his parents. Sandi came home drunk one night. He was noisy, appeared irritated, and verbally abusive towards Bongi. What the boy did not know, and subsequently learnt later, was that this was a regular occurrence. Violence and abuse was a characteristic feature of his mother's marriage. Out of embarrassment and sense of shame, Bongi swore her son to secrecy regarding this violence. She asked him never to breathe a word to his grandmother. Gcobani kept this secret from his grandmother even though he was deeply troubled by this situation. He kept convincing himself that things would get better one day.

One day, Sandi hit Bongi so severely that she fainted in the bedroom. Gcobani thought that his mother was dead and called the neighbours to come to her rescue. They took her to hospital and she recovered. On recovery, Bongi pleaded with Gcobani, once again, not to tell his grandmother. Gcobani wanted to be loyal to his mother but also wondered if he was not an accomplice to her abuse through his silence. This devastated him. He became scared of his parents and developed a hatred for his stepfather. He started devising methods of avenging his mother's abuse. This violence at home affected Gcobani emotionally. He became withdrawn and his performance at school deteriorated. He developed anxiety attacks and nightmares. The grandmother did not know what was wrong with him.

One incident that has etched itself in Gcobani's mind was when he, together with his mother, had to climb down a double storey flat, using an electricity pylon. Bongi was heavily pregnant with 1.Pseudonyms were used in this case study. Participants in the study gave their permission for their stories to be used. 
her third child. They were trying to escape from the abusive, violent and confrontational Sandi. They walked for hours in the night to report this incident to the police station. They had to spend the rest of the night in the cold police station because of unavailability of police vehicles to take them home. At daybreak they walked back home. When they arrived home the violence erupted again. Sandi accused Bongi of spending the night with other men. From this incident Gcobani learnt that Sandi's behaviour arose out of selfish insecurity and jealousy. Gcobani did not realise that this violence to which he was exposed to would ultimately shape his own character and impact negatively on his life as an adult.

Exposure to this kind of violence also affected Bongi negatively. In an act of self-defense, she stabbed Sandi a few times in the chest and abdomen and he was hospitalised. Sandi did not know that whilst violating and abusing his wife, he was creating a monster in her. Not only did she internalise violence as a way of dealing with problems, her character changed drastically. She became emotionally and psychologically withdrawn. She developed an abusive attitude towards her children. She completely lost trust and confidence in men. The perpetuation of violence to which she was exposed to brought about uncharacteristic reactions from her. This, in turn destroyed her children. The cycle of violence had begun to impact not only on the mother but also to shape the children's behavioural tendencies and development.

Bongi turned to alcohol for comfort. She fought physically to defend herself against her assailant. She developed uncontrollable anger and fear that would later render her emotionally unstable. This situation continued for many years until she eventually plucked up the courage to detach herself from this situation. However, it was too late, as the psychological, emotional and physiological damage was already evident in her life. To this day she suffers from anxiety attacks and episodes and extremely bad palpitations. She snaps at her children and grandchildren for no apparent reason. She displays symptoms of emotional instability and vulnerability. These signs are associated with post-traumatic stress disorder (PTSD).

Whilst there is no evidence that Bongi had been exposed to violence as a child, her children's exposure to this violence in her own marriage left them emotionally scarred for life.

\section{Spousal violence and post-traumatic stress disorder}

According to Coetzer (2007):

Post Traumatic Stress Disorder (PTSD) results from exposure to an overwhelming stressful event or series of events, such as war, rape, or abuse. It is a normal response by normal people to an abnormal situation. (p. 36)

The nature of intimate violence and abuse to which Bongi was subjected to was so severe that it overwhelmed her ability to respond adequately. She became incapable of raising her own children effectively. She became emotionally detached towards them. The children, in turn, were distressed to a point of numbness. They became defensive and disrespectful to their mother. They blamed themselves for what was happening in their home.

It has been shown that the psycho-physiological changes of PTSD are both extensive and enduring:

Patients suffer from a combination of generalized anxiety symptoms and specific fears. They do not have a normal level of alert, but relaxed attention. Instead, they have an elevated baseline level of arousal: their bodies are always on the alert for danger. They also have an extreme startle response to unexpected stimuli, as well as an intense reaction to specific stimuli associated with the traumatic event. It also appears that traumatised people cannot 'tune out' repetitive stimuli that other people would find merely annoying; rather, they respond to each repetition as though it were a new, and dangerous surprise. The increase in arousal persists during sleep as well as in the waking state, resulting in numerous types of sleep disturbance. People PTSD take longer to fall asleep, are more sensitive to noise, and awaken more frequently during the night than ordinary people. These traumatic events appear to recondition the human nervous system. (Neuger 2001:108)

Post-traumatic stress symptomatology as described here are the characteristic features of Bongi's life today. People who display such symptoms should receive pastoral counselling - which Bongi did not receive. It could be argued that the same applies to children who have been exposed to chronic intimate violence between their parents. They too, would need pastoral care intervention. Should such intervention be unavailable, these children could manifest post-traumatic stress symptomatology as well.

\section{Impact of exposure to violence on children}

The cycle of violence in the home affects children in many ways. Their continued exposure to parental and relational dysfunctional coping mechanisms shapes their response and behaviour in adult life. This is because they tend to internalise violence and abuse as the norm. For example, Bongi bore five children, all of whom have exhibited different outcomes in their adult life.

Gcobani is the firstborn. He is the only one who is married, well-educated and holds a decent professional career. His sister Nomzamo died in April 2009. She was extremely rebellious in nature and left school in Grade 7. She had four children, all from different fathers. She was an alcoholic and unemployed for all of her life. She lived in debilitating poverty until she died. She was dependent on charity and the goodwill of her extended family. She left her children a legacy of poverty as they have no home or any financial support.

Mbali is Bongi's third child. She has a primary school education. She is unemployed and cohabitates in informal settlements around Cape Town. She conceived and gave 
birth to a baby girl at a very tender age. She dumped her 4-year-old daughter with strangers because she could not take care of her. It is evident from the way Mbali lives that she is uninterested in improving herself. With a limited formal education she cannot find sustainable employment. She has no prospect of a brighter and a meaningful future at present. She, like her late sister Nomzamo, lives in abject poverty and hopelessness. In order to survive she has had to cohabitate with men who offer her financial support, housing and basic life necessities in return for sexual favours. She lives through the cycle of violence in her own relationships as a result of her dependence on these men.

Zolile the fourth child, is now 24 years old. He left school because of a lack of academic progress. He has had unpleasant confrontations with the law and has joined the gangster movement in the Western Cape, South Africa. He also lives in informal settlements. He is the most violent of the siblings and attacked and physically wounded his mother on several occasions. Three times he was beaten to near death by mobs who suspected him of robbery and breaking into their homes.

The fifth child, Azola, is still at Further Education College in Somerset West. There are signs of delinquency and disobedience in him as well. He is however progressing, albeit slowly, and shows signs of hope.

From this history, one can deduce that exposure to violence has negatively impacted on the children. The children tend to think that violence is normal and, because they do not know how to deal creatively with it, they manifest destructive tendencies like delinquency, violence, lack of progress in life and they become a burden to society. Few children get out of the cycle of violence to make a positive contribution in personal and community life. Even those who have done well continue to face challenges.

Consider Gcobani, for example. When he got married, he was very uncertain of himself and not sure of the role and responsibility of a husband, father and a life partner. He was fearful that his own marriage would end up in violent conflict because of what he saw happening in his mother's marriage. Of great concern to him was the fact that he did not have a positive role model from whom he could learn how to raise a family responsibly. He feared that he would fail in his marriage and that he would be a bad example to his children. He was concerned that should things turn out badly, he would not have support from the rest of his extended family. Arising out of this fear and anxiety was the need to work hard in his marriage in order to prove to himself first that he could do it. This is because he did not trust himself enough to carry out the responsibilities, obligations and expectations of bringing up a family. This is how the cycle of violence to which he was exposed affected him in his family life.

How does Gcobani fare in his work environment? He is now an ordained minister in the Methodist Church of Southern Africa (MCSA). He is stationed in a cross-cultural environment. He ministers to a predominantly white, English-speaking congregation in Gauteng, South Africa. As a pastoral care practitioner, he has to offer counselling to people who are living in abusive marriages and relationships. As he listens to their stories, he is reminded of his own story of pain and trauma. In his engagement with these stories, he relives his own trauma and it paralyses him yet again. Feelings of anger, self-blame and inadequacy flood his mind and render him helpless and inadequate as a caregiver. This could be attributed to the fact that he has never dealt with his own pain and trauma that arose as a result of exposure to violence in his family. He has discovered that unless he is healed from his past wounds he will never be able to help others in such situations.

\section{Impact of spousal violence upon children: Literature review}

To what extent are children affected by their exposure to violence within their families? Research has shown that exposure to wife abuse impacts negatively on children (Rossman, Hughes \& Rosenberg 2000:91). This impact is apparent in the following areas: behavioural and traumarelated, emotional, cognitive and school functioning, social skills and attachment functioning.

It is an undisputed fact that children need to be safe and secure in the home environment. Safety and security ensure that they develop a positive sense of self which is necessary for them to grow into healthy, productive, responsible and caring adults. Children need to be safe in their communities as well in order to be able to explore and develop relationships with other people. Children also need to be safe at school in order to learn successfully and be productive in society (Osofsky 1995:1). When that sense of safety and security is compromised the children could grow to be the opposite of what they ought to be. They might not develop positively. Their growth in and contribution to society could be hampered. This is evident in the situation of Gcobani's family.

Studies throughout the world have shown that children who are exposed to violence at home tend to display different symptoms at different stages of their lives. These vary in intensity and range. Children may manifest minor disorders to major dysfunction in their lives. According to Osofsky, very young children may exhibit emotional distress, immature behaviour, somatic complaints, and regressions in toileting and language. They may also display symptoms very similar to PTSD that are usually seen in adults. School-aged children tend to display aggressive delinquent behaviour and withdrawal symptoms. Adolescents tend to display high levels of aggression, acting out, anxiety, behaviour problems, truancy, and revenge-seeking (Osofsky 1995:3-4). The perpetual cycle of violence to which Bongi's children were exposed to brought about some of these symptoms in their lives. 
Whilst some adolescents may be able to overcome their experiences, others suffer considerable scars that may be carried into adulthood. Again, evidence of this observation is found amongst Bongi's children. Some of them have not been able to overcome their experiences. As a result, their adult lives turned out to be a manifestation of their unhealed and unresolved scars. Studies have found that some children may become deadened to feelings and pain, with resultant constrictions in emotional development. Others may attach themselves to peer groups and gangs as substitutes for the family. When they do this, they may incorporate violence as a method of dealing with disputes or frustration (Osofsky 1995:4). Numerous studies in psychology, social work and pastoral care attest to the above. Walker (2002) commented that:

Many children experience or observe violence in their homes or within their neighbourhoods. Their exposure to violence affects their physical health, safety, psychological adjustment, social relations and academic achievement. It also extends beyond emotional and behavioural disorders. It affects the child's view of the world, of himself (or herself), his (her) ideas about the meaning and purpose of life, his (her) expectations of future happiness and moral development. The impact of violence may also affect the individual into adulthood. (p. 20)

Whilst Walker's study concentrates on the impact of community violence on children, her findings are also relevant to children exposed to violence in the home. It could be argued that children who are exposed to violence, whether in the community or at home are '... at significant risk for developing emotional problems. These problems include increased anxiety, depression, difficulty concentrating, inattention, sleep disturbances and symptoms related to posttraumatic stress disorder' (Walker 2002:21). Aggression and self-destructive behaviours have also been reported amongst children exposed to violence. It is clear that children who grow up in violent and dysfunctional environments, whether from family or community, may develop dysfunctional personalities. They may adopt negative coping strategies that would render them 'misfits' or dysfunctional in normal society. They may either be hyperactive or aggressive which may lead to rejection by peers and family. Others may withdraw emotionally, psychologically and socially. These coping strategies could become detrimental not only in the short term but also in the long term development of such children.

Willemse (2008) comes to similar conclusions as Walker. He quotes Barnett who observed that:

... marital violence reveals that children are prone to suffer psychological damage in four areas namely: immediate trauma; adverse effects on development; living under high levels of stress, particularly fear of injury to themselves or their mother and exposure to violent role models. (p. 44)

This is indicative of the negative impact of exposing children to violence within the home: 'When children constantly observe violent actions such as domestic violence, they are deeply affected in their inner being' (Willemse 2008:44). This arises out of the fact that:
Children are also directly beaten in domestic violence or they are indirectly affected when they watch their mother being beaten. It has been reported that about $50 \%$ of the children in violent households are also victims. Some are physically abused, some are sexually abused by their very fathers or other relatives and all are emotionally abused. Some husbands beat their wives in front of their children in order to humiliate them and cover their wives with shame. Observation of such violent acts by the children leaves them profoundly affected in their inner being. The children experience shock and are afraid to do anything while their mother is being beaten. Some children may seek help in order to stop the violence. (Nasimiyu-Wasike 2005:130)

This was the case in Bongi's family. Gcobani would watch helplessly as his mother was being tormented violently by his stepfather. He would sit and think of creative ways in which he could stop this shaming experience of his mother. When he could not, he would feel guilty and angry at himself for being small and unable to take revenge on his mother's behalf. The seed for violent behaviour had already been planted into this young boy's soul.

\section{Nasimiyu-Wasike (2005) observed:}

...[C]hildren who have grown up in domestic violence display nervousness and withdrawal, anxiety, bedwetting, restlessness, low school performance, illnesses such as headaches, stomach complaints, asthma, stuttering, cruelty to animals, copying aggressive language and behaviour in their play, running away from home, teenage boys beating their girlfriends ... children in violent homes come to accept violence as normal. They see violence as a way to cope with stress and pressure. The boys develop disrespect for women and the girls develop inferiority complex. The children could be neglected emotionally. Since the mother spends all her energy struggling just to survive, it has been researched and it is suggested that $50 \%$ to $80 \%$ of men who abuse their wives and/or children, grew up in violent homes. (p. 131).

This demonstrates the depth and gravity of the exposure to violence and abuse on children. Of concern is the fact that these children may continue to perpetuate the cycle of violence in their own homes and families when they grow up.

Netswera (2004:28) comes to a similar conclusion in his study of abuse on children. Netswera identified three distinct patterns of behaviour displayed by abused children in their later lives. They may display destructive, frightened or private behaviour (Netswera 2004:28). These may manifest in violent behaviour, disobedient and maladjusted conduct or passivity, withdrawal and compulsive acts. This suggests that children growing up in abusive backgrounds are affected negatively not only during their childhood but also into their adulthood.

\section{Pastoral care response for the children}

In the preceding sections, we have seen that children who were exposed to violence in their homes were affected negatively, not only whilst they grow up, but also into their adult lives. Such children need an environment in which 
they can heal so that they do not develop into maladjusted, disobedient and abusive adults. The Church (Body of Christ) can play a vital role in this regard. In most communities and cultures, children are taken care of by their mothers. We have noted that if the mothers are abused they cannot fulfill that role meaningfully. Care to the battered women would directly or indirectly benefit the children, especially if the children are still too young to care for themselves personally. Nasimiyu-Wasike (2005) observed:

The Church as a healing community should reach out to battered women, their children and their husbands. The Church should bring God's compassionate and healing presence to such families. Like Christ the Good Shepherd the Church should bring Christ's healing ministry to these families. Jesus in his life here on earth restored many people to wholeness. (p. 132)

Families that are characterised by violence live in a state of constant brokenness and woundedness. Children growing up in such situations carry that brokenness and woundedness into adulthood. They, in turn, perpetrate the injustices in their own families and relationships when they become adults. Unless they are healed, restored and transformed they will not be able to recover their wholeness in the image and likeness of God who created them (Gn 1:27, New International Version Bible). When the Church intervenes, it brings about that much needed healing and wholeness in the lives of the broken and wounded children. As it plays this role it becomes the agent of healing, restoration and transformation.

In bringing about this transformation, the Church must speak prophetically against violence and abuse within families and communities. It must educate with regard to the negative outcomes of violence and abuse not only to those involved but to the society at large. The Church must create a sacred space for victims of abuse and violence, especially women and children, to share their stories in a safe, nonjudgemental, and non-threatening environment. Where possible, the Church must intervene practically to help the victims of violence and abuse. It must be an advocate for human rights of the victims and the voice of the voiceless in situations where other people's dignity and self-worth is undermined. The mission of the Church is:

... [N] tot to encourage battered women (together with their children) to remain in abusive relationships, but rather to rescue them and seek to bring a rebirth in their abusive relationship that will lead to affirmative and healthy relationship. (NasimiyuWasike 2005:132)

This would be a holistic approach to healing for the victims. This approach would restore their sense of dignity and self-worth. It would have a positive 'effect on the suffering people's spiritual, psychosomatic and physical realities' (Nasimiyu-Wasike 2005:132).

On many occasions Gcobani's mother wanted to leave her abusive situation, but she could not because of her economic dependence on her husband. This factor was compounded by the negative consequences associated with someone who is divorced in her Xhosa culture. A divorced woman is called names like umabuy' ekwendeni [the one who has failed in marriage]. Such a woman has no place in the Xhosa culture and tradition. She is subject to ridicule, rejection and shame in the community. Because of that, women who struggle in their relationships are advised and counselled by the elders to persevere. In traditional wedding ceremonies, the woman would be given a shawl or a small blanket as a gift by her family. As the elders put it, this shawl is meant for her to cover up all of the problems she will encounter in her marriage: that means she must not complain about her problems or seek help to address them. She must suffer in silence and bear the pain even if it is unbearable. This thinking goes beyond the socio-cultural contexts to the religious arena. As a result, some churches do not look favourably upon divorcees. In short, they participate in the trauma, abuse and violence through their theological stance. These are some of the reasons that made Bongi stay in a situation that was not conducive for her and her children. She realised that if she left her violent husband she would be a social and a religious outcast.

Advocating against such teaching and culture, NasimiyuWasike (2005) states:

In an abusive relationship, separation may in some instances lead to healing in both the abused and the abuser. The community of believers within which our communion with Christ is rooted is called to endeavour towards bringing about the reign of God by enabling individuals to develop a healing relationship with God, a healing relationship with individual self, with the community, with other individuals and with the world. (Nasimiyu-p. 133)

This will lead to salvation which includes wholeness, healthier personal and social relationships, and a holistic, integral and dynamic way of living. Thus the Church's mission is 'to promote and foster healthy and healing human relationships at public level, Church level and at family level' (Nasimiyu-Wasike 2005:133). This implies that the Church should challenge all evil conditions, especially those caused by violence, abuse, exploitation and irresponsibility. In a situation of abuse and violence, the Church is called not to conduct business as usual. The Church is challenged to stand up and act decisively in addressing such a situation. It must address its theology that keeps women submissive under the authority of (abusive) men. The Church is challenged to adopt an attitude of 'therapeutic and loving liberation rather than that of a judge' (Nasimiyu-Wasike 2005:133).

What is the position regarding divorce? 'Without encouraging divorce, the Church should allow marriages that cannot be reconciled to die. Christ never sanctified suffering but rather he alleviated it whenever and wherever he encountered it' (Nasimiyu-Wasike 2005:135). The Church cannot therefore continue to condemn victims of abuse and violence to suffering by its insistence on them persevering in situations of spousal violence. It has to encourage and even help them to be set free from such degrading and dehumanising 
circumstances. If the Church becomes a place of healing and restoration for the victims of abuse and violence, they will be empowered to be effective contributors in society. If the children who were exposed to violence within their families were to be counselled properly and empowered adequately they would recover and be healed completely to take their rightful place in society as men and women of worth, dignity and value.

Further, in caring pastorally for the victims the Church should:

Support women and children who are victims of domestic violence. Let their problems become our problems. The Church should establish centres where these people can take refuge. Both the abused and the abuser must be helped to search for meaning and authentic values in their concrete context. The Church has to promote respectful dialogue for both parties in order to lead them to Christ who is the Truth, the Life and the Way. (Nasimiyu-Wasike 2005:134)

This quotation indicates the broad role and function of the Church within society. The Church is not just a building in which people meet once a week for worship. The Church is the Body of Christ: people who live in fellowship with God and each other. In this role it should respond to the particular needs and challenges of the society and address these adequately. It should be contributing meaningfully and effectively to community building and advancement, acting as a transforming agent that builds people up and ensures that they develop to contribute meaningfully to the life of communities. That is what the Church is called to be and to do. This is mission in action.

The MCSA's mission statement encapsulates this missionary imperative: 'God calls the Methodist people to proclaim the Gospel of Jesus Christ for healing and transformation' (MCSA 2009:2). From this statement flow the four mission imperatives:

- Evangelism and Church growth

- Spirituality

- Justice and Service

- Human and Economic Development and Empowerment (MCSA 2009:2).

These imperatives are in line with the idea of providing shelter or centres of healing for the abused to take refuge, to receive advocacy and empowerment that Nasimiyu-Wasike calls for. A true Church of Christ has to respond timeously and actively to the challenges that face families characterised by violence:

The Church has to provide pastoral counsellors that will endeavour to direct the abused and the abuser towards Christ and His reign of love and peace. Victims of abuse should have access to centres of counselling services and temporal economic support could be offered to them. Such victims could be enabled to settle down on their own by providing them with skills or some loans to start small businesses. Very often women have no neutral place to run for support. The fear of running away and be branded as prostitutes traps them in a violent relationship. (Nasimiyu-Wasike 2005:134)
It could be argued that Bongi is still haunted by her traumatic experiences of abuse and violence at the hands of her husband. This, in part, could be attributed to the fact that she did not receive counselling and empowerment. She sees herself as a failure and has not recovered from the effects of her abuse. She has vowed never to get married again because she has trust issues when it comes to men. She sees and regards men as monsters and therefore unworthy of love and respect. She has not learnt to overcome the humiliation, torture, disrespect and psychological trauma that she was subjected to. To that effect, Nasimiyu-Wasike's observation is helpful if taken seriously. She says that these women need to be educated into rejecting humiliation, ridicule and psychological and physical torture. They have to develop self-assertiveness (Nasimiyu-Wasike 2005:135). This can only be achieved if they receive proper counselling. This would apply to their children too.

These victims also need to be encouraged to become counsellors themselves through support groups. Louw and Louw (2011:32) observed that support groups and friendship circles were beneficial in the recovery process for victims of trauma. They stated that 'in a support group it is not only about what you can receive, but also about what you can give' (Louw \& Louw 2011:32). Through support groups, these women can encourage and empower each other. By so doing they would be catalysts for each other's progress towards healing, rehabilitation and restoration. Such groups can be established within the Church or within communities.

The faith community needs to offer, through a process known as positive deconstruction, hope to children who had been exposed to violence. The children would need to internalise a new way of responding to life and coping with their experiences. Positive deconstruction, whilst not necessarily coined with children of spousal violence in mind, would be helpful. According to Pollard (1997):

the process is 'deconstruction' because I am helping people to deconstruct (that is, take apart) what they believe in order to look carefully at the belief and analyse it. The process is 'positive' because this deconstruction is done in a positive way - in order to replace it with something better. (p. 44)

Children who had been exposed to intimate violence between their parents need to be empowered to deconstruct the worldview of violence, intimidation, neglect, shame, trauma and emotional disengagement they have come to accept as normal and reconstruct a new world view based on love, acceptance, self-worth and dignity. Through interaction, engagement, acceptance and active listening, these children would begin to take apart their experience of the past and replace it with a new way of responding to their situation. They would be able to reconstruct positive images of life and coping mechanisms. The process of positive deconstruction would be helpful to them because it 'recognizes and affirms the elements of truth to which individuals already hold, but also helps them to discover for themselves the inadequacies of the underlying worldviews they have absorbed' (Pollard 1997:44). 
Through effective pastoral care and positive role modeling and mentoring, the faith community would be able not only to manage the symptoms of growing up in a family background of brokenness but also to shape a new reality to which these children would look forward. Positive deconstruction would help them develop a new sense of identity. Such an identity will give them a renewed sense of confidence in the face of trauma and dehumanising circumstances. In finding a relationship with God through the worshipping community, traumatised children know that they are loved perfectly. As they know they are themselves deeply loved, they will be able to internalise something new that gives them hope in the world.

\section{Conclusion}

This article was an investigation into the impact of exposing children to violence in their homes. It was discovered that such children are affected negatively, not only during childhood but also into adulthood. When that happens, their relationships, productivity, general conduct and behaviour becomes counterproductive to life. Healing, restoration, wholeness and transformation are possible for these children if they are cared for, nurtured, mentored and looked after within the fellowship of the Church.

This article developed a pastoral care response to the plight of these traumatised victims. Entailed in this response are activities such as:

- The Church of Christ (body of believers) reaching out in intentional missionary activities to the victims and perpetrators of traumatic conflict, abuse and violence. This would bring about healing, restoration and wholeness to both the victims and the perpetrators.

- The Church actively and intentionally prophesying against the evils of exposure to violence of the children with their families.

- Educating societies, communities and individuals about the negative effects of violence on children: advocating for restoration of ethical values and moral standards within families and communities. Included in this education would be addressing the theology of the Church that continues to proclaim that women are inferior and therefore should be submissive to the authority of abusive men.
- Creating sacred space within the worshipping community for victims of violence to share their stories, vent their frustrations and receive unconditional acceptance from the people of God. Such space can be offered during the worship service in the form of testimony sharing or in small group support and accountability groups.

- Promotion and fostering healthy and healing human relationships at family, church, society and public levels.

- Promoting positive deconstruction of the violent worldview to which the children were exposed. Practical interventions such as advocating for human rights and dignity; establishment of centres of healing or counselling houses and shelters meant for the victims to move away from the dehumanising and traumatic homes; and economic empowerment programmes for women so that they do not persevere in traumatic situations as a result of dependence on their abusive spouses.

\section{Acknowledgements Competing interests}

The authors declare that they have no financial or personal relationship(s) that may have inappropriately influenced them in writing this article.

\section{Authors' contributions}

This article has been adapted from L.G.S.'s (University of Pretoria) MA dissertation, which was completed under the supervision of M.J.M. (University of Pretoria), South Africa.

\section{References}

Coetzer, W., 2007, 'Trauma counselling', unpublished document, Potchefstroom. Louw, B. \& Louw, W., 2011, Put trauma behind you, Aquilla Advisors, Pretoria. Methodist Church of Southern Africa (MCSA), 2009, Yearbook and directory, Methodist Publishing House, Cape Town.

Nasimiyu-Wasike, A., 2005, Domestic violence against women - A cry for life in wholeness, D. Waruta \& H. Kinoti (eds.), Acton Publishers, Nairobi.

Netswera, L.A., 2004, Caring for the abused children is the responsibility of the nation: A practical theological investigation, University of Pretoria, Pretoria.

Neuger, C.C., 2001, Counseling women: A narrative pastoral approach, Fortress Publishers, Minneapolis.

Osofsky, J.D., 1995, 'Children who witness domestic violence: the invisible victims', Society for Research in Child Development IX(3), 1-20.

Pollard, N., 1997, Evangelism made slightly less difficult, Inter-Varsity Press, Leicester. Rossman, B.B.R., Hughes, H.M. \& Rosenberg, M.S., 2000, Children and interparental violence - The impact of exposure, Taylor and Francis Group, Philadelphia.

Walker, D.A., 2002, The exposure to violence experienced by grade three pupils in Gauteng, University of Pretoria, Pretoria.

Willemse, E., 2008, Traumatic violence that leads to family murder by fathers - A challenge to pastoral care, University of Pretoria, Pretoria. 